\title{
Circulating miR-3659 may be a potential biomarker of dyslipidemia in patients with obesity
}

\author{
Liu Miao ${ }^{1}$, Rui-Xing Yin ${ }^{1 *}$, Shang-Ling Pan², Shuo Yang ${ }^{1}$, De-Zhai Yang ${ }^{3}$ and Wei-Xiong Lin ${ }^{3}$
}

\begin{abstract}
Background: The present study attempted to identify potential key genes and miRNAs of dyslipidemia in obese, and to investigate the possible mechanisms associated with them.

Methods: The microarray data of GSE66676 were downloaded, including 67 obese samples from the Gene Expression Omnibus (GEO) database. The weighted gene co-expression network (WGCNA) analysis was performed using WGCNA package and grey60 module was considered as the highest correlation. Gene Ontology annotation and the Kyoto Encyclopedia of Genes and Genomes (KEGG) pathway enrichment analyses for this module were performed by clusterProfiler and DOSE package. A protein-protein interaction (PPI) network was established using Cytoscape software, and significant modules were analyzed using molecular complex detection.
\end{abstract}

Results: Collagen type I alpha 1 chain gene (COL1A1) had the best significant meaning. After bioinformatic analysis, we identified four miRNAs (hsa-miR-3659, hsa-miR-4658, hsa-miR151a-5p and hsa-miR-151 b) which can bind SNPs in 3'UTR in COL1A1. After validation with RT-qPCR, only two miRNAs (hsa-miR-3659 and hsa-miR151a-5p) had statistical significance.

Conclusions: The area of 0.806 for miR-3659 and 0.769 for miR-151a-5p under the ROC curve (AUC) may have good diagnostic value for dyslipidemia. Circulating miR-3659 may be a potential biomarker of dyslipidemia in patients with obesity.

Keywords: Gene Expression Omnibus, Weighted gene co-expression network analysis, Dyslipidemia, Obesity, COL1A1, miR-3659

\section{Background}

Obesity, especially abdominal obesity, is the key reason to result in metabolic syndrome (MetS), which refers to insulin resistance, type 2 diabetes mellitus, hypertension, and dyslipidemia, and all above risk factors finally lead to cardiovascular disease $[1,2]$. A recent study showed that about 2.2 billion people were overweight or obese in 2015 [3]. As a complex and multifactorial disease, lots of environmental and genetic factors can result in this disorder $[4,5]$.

\footnotetext{
*Correspondence: yinruixing@163.com

${ }^{1}$ Department of Cardiology, Institute of Cardiovascular Diseases, The First Affiliated Hospital, Guangxi Medical University, Nanning 530021, Guangxi, People's Republic of China

Full list of author information is available at the end of the article
}

MicroRNA (miRNA), a class of non-coding RNA molecules ( 22 nucleotides), is short and highly conserved. When it dysregulated, lots of human diseases would be happened [6]. MiRNAs mediate post-transcriptional regulation of protein-coding genes by complementary binding to the $3^{\prime}$ untranslated region ( $3^{\prime}$ UTR) and occasionally to the $5^{\prime} \mathrm{UTR}$ or coding regions of target mRNAs [7]. Previous study has shown that single nucleotide polymorphisms (SNPs) in the miRNA regulatory networks were a novel class of functional variants in the human genome. Genetic variants that potentially influence miRNA-mediated cellular function may be classified in two major categories: SNPs affecting miRNA biogenesis and SNPs in the miRNA targetome $[8,9]$.

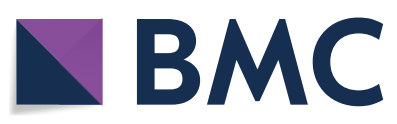

(c) The Author(s) 2019. This article is distributed under the terms of the Creative Commons Attribution 4.0 International License (http://creativecommons.org/licenses/by/4.0/), which permits unrestricted use, distribution, and reproduction in any medium, provided you give appropriate credit to the original author(s) and the source, provide a link to the Creative Commons license, and indicate if changes were made. The Creative Commons Public Domain Dedication waiver (http://creativecommons.org/ publicdomain/zero/1.0/) applies to the data made available in this article, unless otherwise stated. 
Early detection and treatment contribute to a promising effect. Since the discovery of circulating miRNAs in body fluids, an increasing number of studies have focused on their potential and non-invasive biomarkers, and therapeutic targets or tools for many diseases [10]. Martino et al. found that both miR-33a and miR-33b were early biomarkers for cholesterol levels in childhood [11]. Besides, Iacomino et al. had further found about the role of miRNAs in obesity and related metabolic abnormalities [12]. In this study, we performed the integrated bioinformatic methods to construct the co-expression network and mark significant miRNA. The outcomes may help us for further elucidating the innate character of dyslipidemia, and provide new insights to potential biomarkers and signaling pathways to treat dyslipidemia in obese.

\section{Materials and methods Microarray data}

Microarray data of GSE66676 [13] were downloaded from the National Center for Biotechnology Information (NCBI) Gene Expression Omnibus (GEO, http://www. ncbi.nlm.nih.gov/geo/) database [14]. GSE66676 contains 67 Liver wedge biopsy samples from obesity patients (mean age $=16.88$, mean body mass index, BMI $=52.01$ ). The CEL files were transformed into the expression value matrix using the Affy package in R [15], and the probe information was then transformed into the gene name using Bioconductor in R [16]. If one gene had more than one probe, the mean expression value of this gene was selected. The specific workflow is shown in Fig. 1.

\section{Construction of weighted gene co-expression network}

The weighted gene co-expression network (WGCNA) is a widely used systems biology method, which is used to construct a scale-free network from gene expression data [17]. An appropriate soft threshold power (soft power $=6$ ) was selected in accordance with standard scale-free networks, with which adjacencies between all differential genes were calculated by a power function [18]. The rest of the analysis strategy can refer to our previous research [19].

\section{Finding module of interest and functional annotation}

The correlation between modules and clinical features was evaluated by Pearson's correlation tests to search biologically meaningful modules. The module and clinical feature, which exhibited the highest correlation, were selected as module of interest and clinical feature to be studied. All genes of module of interest were analyzed by Gene Ontology (GO) and Kyoto Encyclopedia of Genes and Genomes (KEGG) pathway by clusterProfiler and

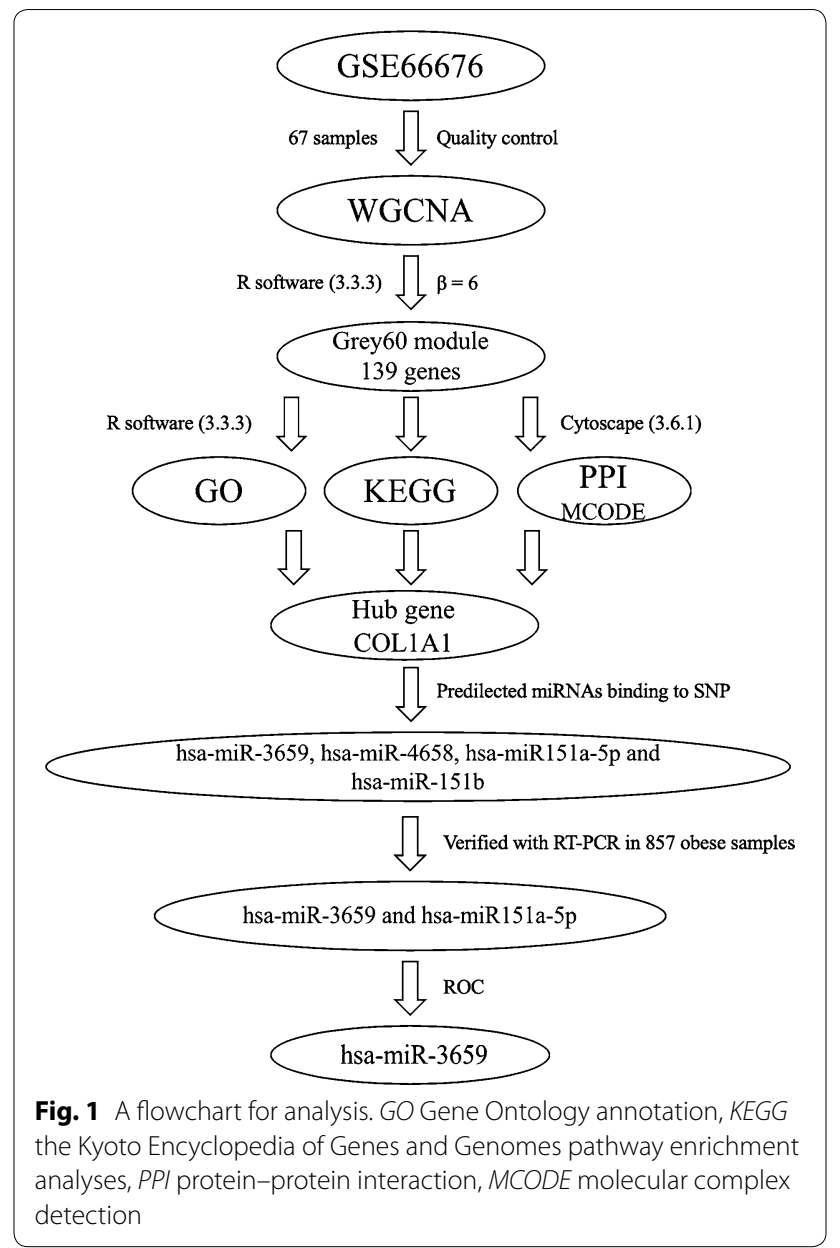

DOSE package in R [20]. A $P$ value $<0.01$ and false discovery rate $(\mathrm{FDR})<0.05$ were set as the cutoff criteria.

\section{Hub gene analysis}

The module membership (MM) was defined as the correlation of gene expression profile with module eigengenes (Mes). And the gene significance (GS) measure was defined as (the absolute value of) the correlation between gene and external traits. Genes with highest MM and highest GS in modules of interest were natural candidates for further research [21]. Thus, the intramodular hub genes were chosen by external traits based GS $>0.2$ and $\mathrm{MM}>0.6$ with a threshold of $P$-value $<0.05$ [17]. The gene-gene interaction network was constructed and visualized using Cytoscape software package [22] and molecular complex detection (MCODE) [23] was used to analyze the most notable clustering module. MCODE score $>6$ was a threshold for next analysis.

\section{Subjects}

All of the two groups of study population were obese, including 424 unrelated participants of normals (128 
males, $30.19 \%$ and 296 females, $69.81 \%$ ) and 433 unrelated subjects of dyslipidemia (141 males, $32.56 \%$ and 292 females, 67.44\%) were recruited from hospitalized patients in the First Affiliated Hospital, Guangxi Medical University [24]. The participants' age ranged from 18 to 80 years with a mean age of $55.31 \pm 10.52$ years in normal and $55.87 \pm 11.13$ years in dyslipidemic groups; respectively. The gender ratio and age distribution were matched between the two groups. All participants were essentially healthy with no history of coronary artery disease, stroke, diabetes, hyper- or hypo-thyroids, and chronic renal disease. They were free from medications known to affect lipid profiles.

\section{Epidemiological survey}

The epidemiological survey was carried out using internationally standardized method, following a common protocol [25]. Cigarette smoking status was categorized into groups of cigarettes smoker and non-smoker. Alcohol consumption was categorized into groups of alcohol drinker and non-drinker [26]. Several parameters such as blood pressure, height, weight and waist circumference (WC) were measured, while BMI $\left(\mathrm{kg} / \mathrm{m}^{2}\right)$ was calculated.

\section{Biochemical measurements}

Venous blood samples were obtained from all subjects after at least $12 \mathrm{~h}$ of fasting. The levels of serum total cholesterol (TC), triglyceride (TG), high-density lipoprotein cholesterol (HDL-C), and low-density lipoprotein cholesterol (LDL-C) in samples were determined by enzymatic methods with commercially available kits, Tcho-1, TG-LH. Cholestest HDL, and Cholestest LDL, respectively. Serum apolipoprotein (Apo) A1 and ApoB levels were detected by the immunoturbidimetric immunoassay. All determinations were performed with an autoanalyzer in the Clinical Science Experiment Center of the First Affiliated Hospital, Guangxi Medical University [27].

\section{Diagnostic criteria}

The normal values of serum TC, TG, HDL-C, LDL-C, ApoA1, ApoB levels and the ApoA1/ApoB ratio in our Clinical Science Experiment Center were 3.10-5.17, $0.56-1.70, \quad 0.91-1.81, \quad 2.70-3.20 \mathrm{mmol} / \mathrm{L}, \quad 1.00-1.78$, $0.63-1.14 \mathrm{~g} / \mathrm{L}$, and $1.00-2.50$; respectively. Hypertension was diagnosed according to the criteria from the 1999 World Health Organization-International Society of Hypertension Guidelines for the management of hypertension [28]. The diagnostic criteria of overweight and obesity were according to the Cooperative Meta-analysis Group of China Obesity Task Force. Normal weight, overweight and obesity were defined as a $\mathrm{BMI}<24$, $24-28$ and $>28 \mathrm{~kg} / \mathrm{m}^{2}$, respectively [29]. Dyslipidemia was defined according to World Health Organization criteria: $\mathrm{TG} \geq 1.7 \mathrm{mmol} / \mathrm{L}$ and HDL-C $<0.9 \mathrm{mmol} / \mathrm{L}$ for men or $<1.0 \mathrm{mmol} / \mathrm{L}$ for women. Diabetes was defined as a fasting plasma glucose $\geq 7.0 \mathrm{mmol} / \mathrm{L}$ or $2 \mathrm{~h}$ postprandial plasma glucose $\geq 11.1 \mathrm{mmol} / \mathrm{L}$ or as having been previously diagnosed with diabetes and receiving therapy [30].

\section{Bioinformatic analysis of miRNAs binding to SNP and linkage disequilibrium analysis}

Bioinformatic software (http://bioinfo.life.hust.edu.cn/ miRNASNP2/) was used to detect the candidate SNPs which could affect COL1A1 regulation via miRNAs [31].

\section{RNA isolation}

Fasting blood samples $(5 \mathrm{~mL})$ were collected in EDTA and separated by centrifugation at $3000 \mathrm{~g}$ for $15 \mathrm{~min}$. Total RNA containing miRNAs was isolated from plasma using the miRNeasy serum/plasma kit (TIANGEN: catalog number DP503, China). The homogenate was incubated for $5 \mathrm{~min}$ at room temperature, $25 \mathrm{fmol}$ of synthetic celmiR-39 (TIANGEN; catalog number: CD200-01, China) was spiked in. Subsequently, the RNA was extracted according to the manufacturer's protocols. Total RNA was eluted in $30 \mu \mathrm{L}$ of RNase-free water. RNA was reverse transcribed to CDNA with reverse transcriptase kit (TIANGEN; catalog number: KR211, China). The reaction system contained total RNA $2 \mu \mathrm{g}$, miRNA RT reaction buffer $10 \mu \mathrm{L}$, Enzyme Mix $2 \mu \mathrm{L}$, RNase-free water up to $20 \mu \mathrm{L}$. The mixture was incubated at $42^{\circ} \mathrm{C}$ for $60 \mathrm{~min}, 95^{\circ} \mathrm{C}$ for $3 \mathrm{~min}$, and then held at $4{ }^{\circ} \mathrm{C}$. A no-RT negative control was included in each experiment to ensure that PCR products were not due to contamination by genomic DNA.

\section{Reverse transcription (RT) and quantitative PCR (qPCR)}

The quantification of 4 plasma miRNAs was measured by SYBR Green-based real-time PCR using a miScript SYBR Green PCR kit (TIANGEN; catalog number FP411, China). The reaction contained $2 \times$ miRcute Plus miRNA Premix $10 \mu \mathrm{L}, 0.2 \mu \mathrm{L}$ PCR Forward Primer, 0.4 $\mu \mathrm{L}$ PCR Reverse Primer, $3.0 \mu \mathrm{L}$ cDNA, RNase-free water up to $20 \mu \mathrm{L}$. The reactions were incubated at $95{ }^{\circ} \mathrm{C}$ for $15 \mathrm{~min}$, $94{ }^{\circ} \mathrm{C}$ for $20 \mathrm{~s}, 60^{\circ} \mathrm{C}$ for $30 \mathrm{~s}, 72{ }^{\circ} \mathrm{C}$ for $34 \mathrm{~s}$. All reactions were run in duplicate. The average of the $\mathrm{Ct}$ value was calculated after the PCRs were run in duplicate for each sample. The cel-miR-39 value from the duplicate was used as the internal control [32]. The relative expression of each miRNA after normalization to cel-miR-39 is displayed as $2^{-[\mathrm{Ct}(\mathrm{miRNA})-\mathrm{Ct}(\mathrm{cel}-\mathrm{miR}-39)]}$.

\section{Statistical analysis}

All statistical analyses were performed using the statistical software package SPSS 21.0 (SPSS Inc. Chicago, 
IL, USA) and R software (version 3.3.3). A Chi square analysis was used to evaluate the difference of the rate between the groups. Continuous data were presented as mean $\pm \mathrm{SD}$. For those, that are normally distributed, whereas the medians and interquartile ranges for TG, which is not normally distributed. Comparisons between groups for continuous data were made using MannWhitney nonparametric tests. The heart-map of correlation models and Bioinformatic analysis was measured by $\mathrm{R}$ software (version 3.3.3). The receiver operating characteristic (ROC) curve analysis was performed with plasma miR-3659 and miR-151a-5p to distinguish between dyslipidemia and control groups. The AUC was estimated to assess the diagnostic performance of miR-3659 and miR151a-5p. All tests were two-sided, and $P<0.05$ was considered statistically significant.

\section{Results}

\section{Data preprocessing}

When the GSE66676 was analyzed, we can get 54560 expression probes separately from each gene expression profile. After data preprocessing, the expression matrices of 19938 genes were obtained from the 67 samples. All of the genes and the samples' phenotype were shown in Additional file 1: Tables S1 and S2.

\section{Weighted gene co-expression networks}

We selected soft-threshold $\beta=6$ to construct gene modules using the WGCNA package (Additional file 2: Figure S1). After determining the soft threshold, all of genes were used to construct weighted gene co-expression networks. Then, we calculated the correlation matrix and adjacency matrix of the gene expression profile of the four lipid-profile groups, and then transformed them into a topological overlap matrix (TOM), and obtained a system clustering tree of genes on the basis of gene-gene non- $\omega$ similarity. Together with the TOM, we performed the hierarchical average linkage clustering method to identify the gene modules of each gene network (deepsplit $=2$, cut height $=0.25$ ). Six gene modules were recognized by the dynamic tree cut (Fig. 2).

\section{Finding module of interest and functional annotation}

It is a hugely valued biological significance to find out modules most significantly associated with clinical features. The highest association in the Module-feature relationship was found in grey60 module and TG $\left(r^{2}=0.98\right.$, $P=7 \mathrm{E}-04)$, which was selected as module of interest and clinical feature to be studied in subsequent analyses (Fig. 3). The other modules without enough relationship or statistical significance for further consideration. In order to explore biological relevance of grey60 module, 139 genes which can be found in this module (Additional file 1: Table S3) were respective subjected to Gene Ontology (GO) functional and KEGG pathway enrichment analyses by $\mathrm{R}$ clusterProfiler package [20]. Biological processes, cell component, molecular function and KEGG pathway analysis of grey60 module were shown in Fig. 4. All of the databases were shown in Additional file 1: Tables S4 and S5.

\section{Protein-protein interaction (PPI) network construction and identify hub genes}

When the STRING database [33] was analyzed, a total of 64 nodes and 179 protein pairs were got with a combined weight score $>0.25$ in grey60 module (Fig. 5). After analysis in sub-module, only two modules with score $>6$ were detected by MCODE. As shown in triangle cluster, COL1A1 had the highest score (Degree $=34$, MCODE $=10.25)$. We hypothesized that COL1A1 as the hub gene was closely relevant to dyslipidemia occurs.

\section{Demographic and biochemical characteristics}

Demographic, epidemiological and clinical characteristics of the 857 analyzed study subjects are summarized in Table 1. All of the subjects were obese. The levels of weight, WC, BMI, systolic blood pressure (SBP), diastolic blood pressure (DBP), pulse pressure (PP), serum glucose, TC, TG, LDL-C and the percentages of diabetes and hypertension were higher, whereas the HDL-C levels were lower in dyslipidemia group as compared with normals.

\section{Identification of COL1A1 polymorphisms in 3'-UTR SNPs}

In this study, we mainly focused on the relationship of the SNPs in the COL1A1 3'-UTR to dyslipidemia risk and outcome. We first searched the GenBank of Single Nucleotide Polymorphism database (https://www.ncbi.nlm.nih. gov/snp) to identify potential COL1A1 genetic variants in the $3^{\prime}$-UTR using the following parameters: Organism (Homo sapiens); Function Class ( $3^{\prime}$-UTR); Global MAF (0.01-0.1); Validation Status (by-1000 Genomes). We identified four COL1A1 polymorphisms (Fig. 6).

\section{Expression level of four miRNAs between the two groups} As compared with those of healthy controls, the relative expression levels of circulating miR-3659 and miR151a-5p in dyslipidemic patients were significantly increased $(P<0.05$; Fig. 6$)$.

\section{ROC curve for dyslipidemia}

We performed a ROC analysis to determine the predictive values of miR-3659 and miR-151a-5p for dyslipidemia. The AUCs of miR-3659 and miR-151a-5p were 0.806 (95\% CI $0.769-0.844 ; P<0.001)$ and 0.769 (95\% CI $0.729-0.808 ; P<0.001)$, respectively. This indicated that 


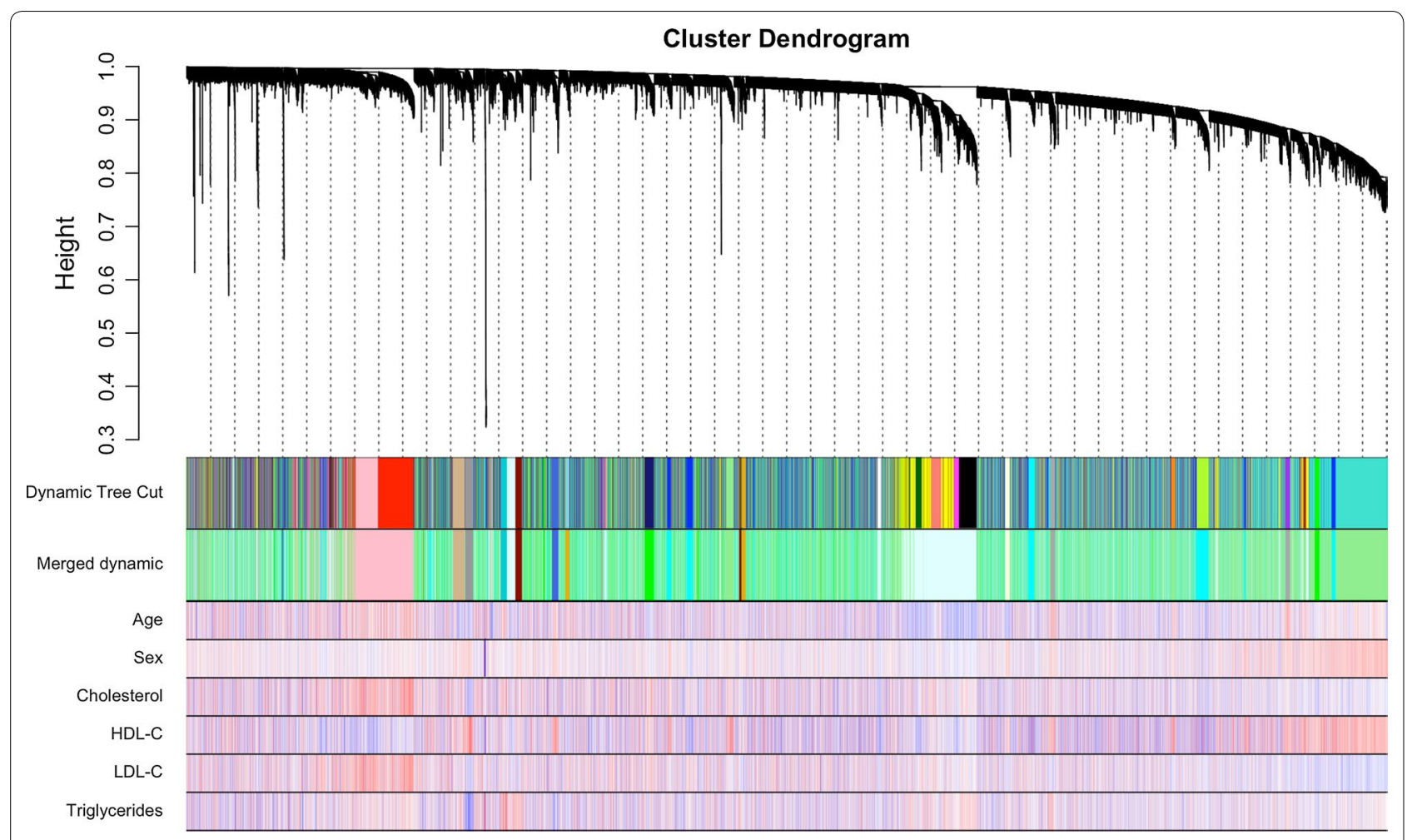

Fig. 2 Clustering dendrogram of genes. Gene clustering tree (dendrogram) obtained by hierarchical clustering of adjacency-based dissimilarity. The colored row below the dendrogram indicates module membership identified by the dynamic tree cut method, together with assigned merged module colors and the original module colors. And, below is the phenotype. $H D L$-C high-density lipoprotein cholesterol, $L D L-C$ low-density lipoprotein cholesterol

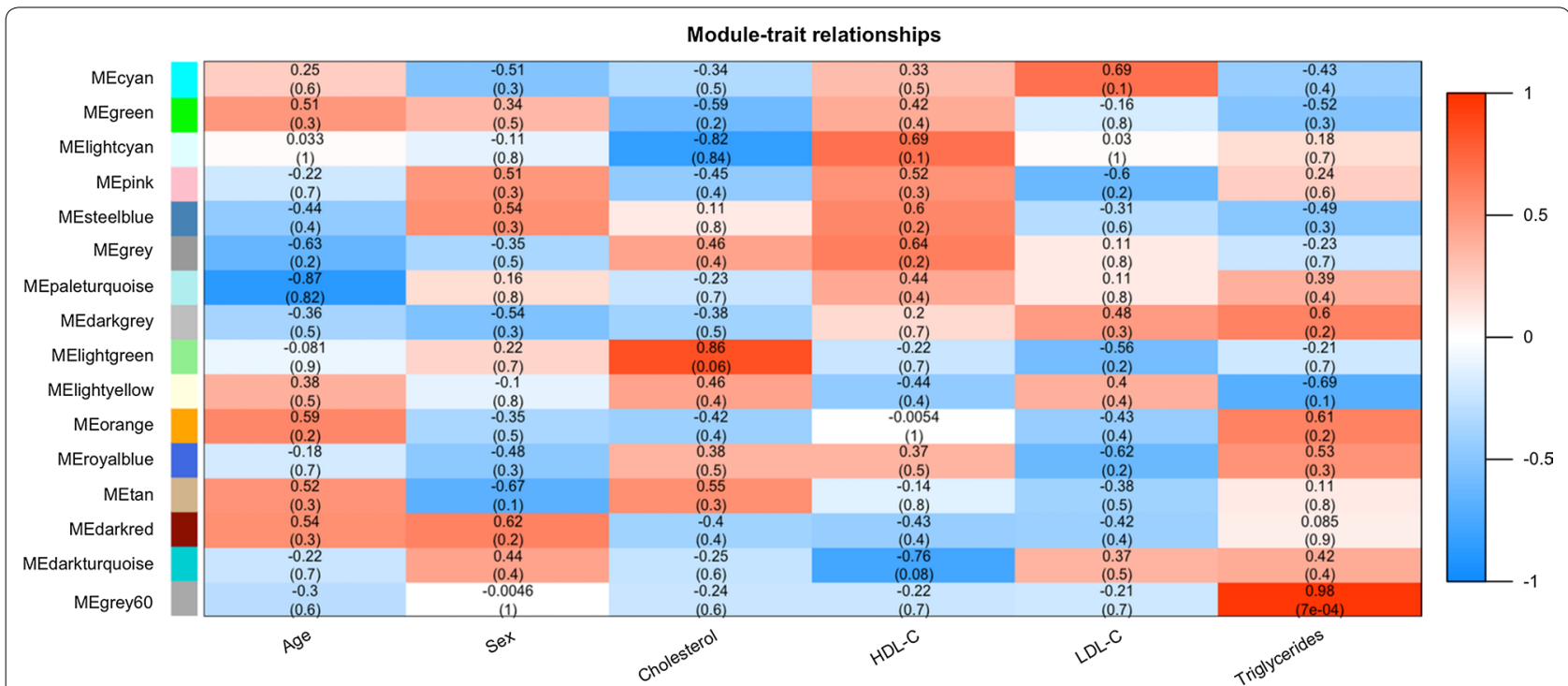

Fig. 3 Module-feature associations. Each row corresponds to a module Eigengene and each column to a clinical feature. Each cell contains the corresponding correlation in the first line and the $P$-value in the second line. The table is color-coded by correlation according to the color legend 

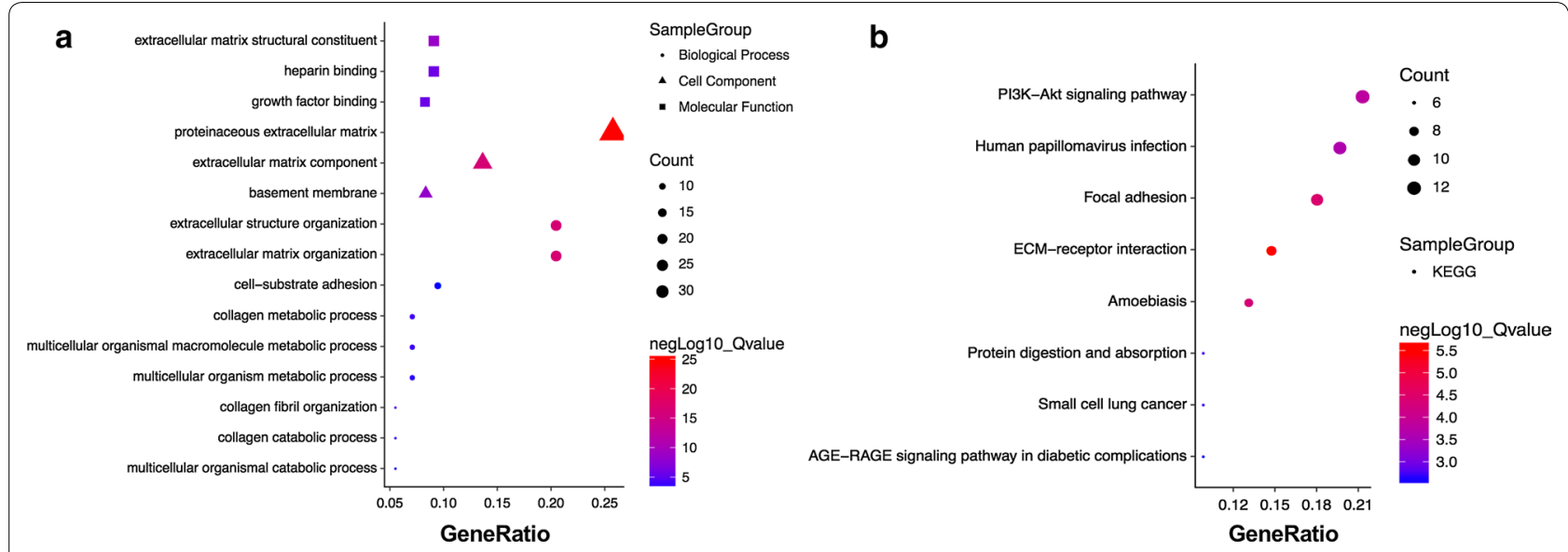

Fig. 4 GO functional and KEGG pathway enrichment analyses for genes in the object module. The $x$-axis shows the ratio number of genes and the $y$-axis shows the GO and KEGG pathway terms. The $-\log _{10}$ ( $P$-value) of each term is colored according to the legend. GO Gene Ontology annotation, KEGG the Kyoto Encyclopedia of Genes and Genomes pathway enrichment analyses

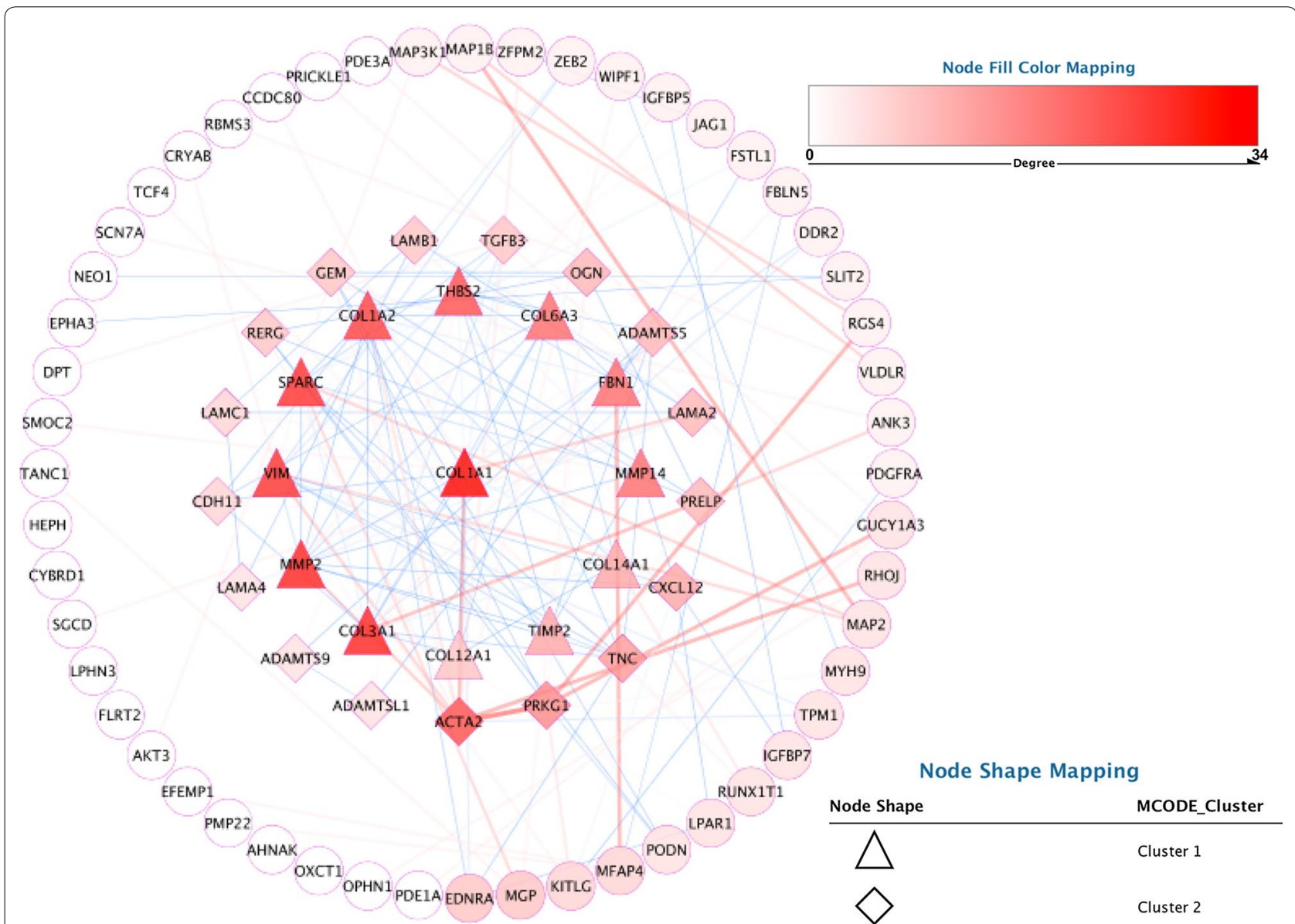

Fig. 5 The protein-protein interaction analysis of the differentially expressed genes. Protein-protein interaction network of the module genes. Edge stands for the interaction between two genes. A degree was used for describing the importance of protein nodes in the network, red shows a high degree and blue presents a low degree. The significant two modules identified from the protein-protein interaction network shown with triangle (cluster 1) and diamond (cluster 2) using the molecular complex detection method with a score of $>6.0$ 
Table 1 Comparison of demographic, lifestyle characteristics and serum lipid levels between the normal and dyslipidemia groups in obese

\begin{tabular}{|c|c|c|c|c|}
\hline Parameter & Normal & Dyslipidemia & Test-statistic & $P$ \\
\hline Number & 424 & 433 & & \\
\hline Male/female & $128 / 296$ & $141 / 292$ & 0.561 & 0.454 \\
\hline Age (years) ${ }^{a}$ & $55.31 \pm 10.52$ & $55.87 \pm 11.13$ & 0.987 & 0.378 \\
\hline Height (cm) & $156.13 \pm 6.94$ & $155.63 \pm 7.02$ & 1.496 & 0.192 \\
\hline Weight (kg) & $52.83 \pm 7.94$ & $61.74 \pm 10.64$ & 25.439 & $1.73 \mathrm{E}-06$ \\
\hline Body mass index $\left(\mathrm{kg} / \mathrm{m}^{2}\right)$ & $29.49 \pm 3.13$ & $31.31 \pm 4.54$ & 31.224 & $2.56 \mathrm{E}-08$ \\
\hline Waist circumference (cm) & $74.23 \pm 6.91$ & $86.55 \pm 9.47$ & 22.321 & $3.11 \mathrm{E}-05$ \\
\hline \multicolumn{5}{|l|}{ Smoking status $[n(\%)]^{b}$} \\
\hline Non-smoker & $306(72.2)$ & $325(75.1)$ & & \\
\hline Smoker & $118(27.8)$ & $108(24.9)$ & 0.920 & 0.337 \\
\hline \multicolumn{5}{|l|}{ Alcohol consumption [n (\%)] } \\
\hline Non-drinker & $339(80.1)$ & $330(76.2)$ & & \\
\hline Drinker & $85(19.9)$ & $103(23.8)$ & 1.750 & 0.186 \\
\hline Systolic blood pressure (mmHg) & $128.24 \pm 18.18$ & $136.47 \pm 22.16$ & 43.136 & $6.13 \mathrm{E}-012$ \\
\hline Diastolic blood pressure (mmHg) & $81.54 \pm 10.16$ & $86.49 \pm 13.15$ & 18.250 & $7.39 \mathrm{E}-05$ \\
\hline Pulse pressure $(\mathrm{mmHg})$ & $49.64 \pm 14.28$ & $52.42 \pm 17.59$ & 28.317 & $3.63 \mathrm{E}-07$ \\
\hline Glucose (mmol/L) & $5.94 \pm 1.83$ & $7.15 \pm 2.45$ & 19.817 & $5.91 \mathrm{E}-05$ \\
\hline Total cholesterol (mmol/L) & $4.94 \pm 1.13$ & $5.14 \pm 1.07$ & 7.121 & 0.029 \\
\hline Triglyceride $(\mathrm{mmol} / \mathrm{L})^{c}$ & $1.49(0.51)$ & $1.78(1.22)$ & 8.441 & 0.021 \\
\hline $\mathrm{HDL}-\mathrm{C}(\mathrm{mmol} / \mathrm{L})$ & $1.54 \pm 0.49$ & $1.06 \pm 0.27$ & 8.668 & 0.013 \\
\hline LDL-C (mmol/L) & $2.84 \pm 0.84$ & $2.88 \pm 0.79$ & 9.497 & 0.007 \\
\hline ApoA1 (g/L) & $1.33 \pm 0.25$ & $1.29 \pm 0.27$ & 0.364 & 0.558 \\
\hline ApoB (g/L) & $0.82 \pm 0.19$ & $0.86 \pm 0.20$ & 1.492 & 0.233 \\
\hline ApoA1/ApoB & $1.67 \pm 0.50$ & $1.66 \pm 0.57$ & 0.095 & 0.758 \\
\hline Diabetes $[n(\%)]$ & $47(11.0)$ & $64(14.9)$ & 9.444 & 0.010 \\
\hline Hypertension [n (\%)] & $197(46.4)$ & $213(49.3)$ & 8.457 & 0.019 \\
\hline
\end{tabular}

$H D L-C$ high-density lipoprotein cholesterol, LDL-C low-density lipoprotein cholesterol, Apo apolipoprotein

a Continuous data were presented as mean \pm SD and determined by two side $t$-test

b A Chi square analysis was used to evaluate the difference of the rate between the groups

c For those, that are normally distributed, whereas the medians and interquartile ranges for TG, was determined by the Wilcoxon-Mann-Whitney test

the diagnostic performance of the miR-3659 was superior to miR-151a-5p $(P=0.02026$; Fig. 7$)$.

\section{Discussion}

Several recent reports showed that age, gender, smoking, obesity, dyslipidemia, lack of exercise, hypertension and diabetes mellitus are established risk factors for cardiovascular disease [34, 35]. With the remarkable improvement of social living standard, obesity has turned into a worldwide epidemic [36]. As a complex and multifactorial disease, lots of environmental and genetic factors can result in obesity and dyslipidemia $[37,38]$. In the current study via WGCNA analysis, we have identified that COL1A1 may modify serum lipid levels in obese patients.

Type 1 collagen is the main structural protein of bone and is encoded by two genes: COL1A1 and COL1A2. The COL1A1 is located in chromosome 17, region 17q2122 , and presents 51 exons. One of the most extensively studied polymorphisms is the so-called Sp1, which consists of the substitution of a guanine (G) by a thymine $(\mathrm{T})$ in the first base of the first intron of the gene, which affects the binding site of the transcription factor Sp1 and thereby, the regulation of the gene transcription [39]. Besides this, a recent research found that COL1A1 polymorphisms could modify blood lipid levels, especially TG [40]. Previous studies also showed that the typical dyslipidemia of obesity consists of increased TG and free fatty acid, decreased HDL-C with HDL dysfunction and normal or slightly increased LDL-C with increased small dense LDL [41]. Therefore, in obese, when the COL1A1 expression changed, it may lead to serum TG increased and cause dyslipidemia.

MiRNAs, the endogenous and small noncoding RNAs, were found in lots of cell types and tissues especially the adipose tissue [42]. Besides, miRNAs may play an important role in the regulation of physiological and metabolic 


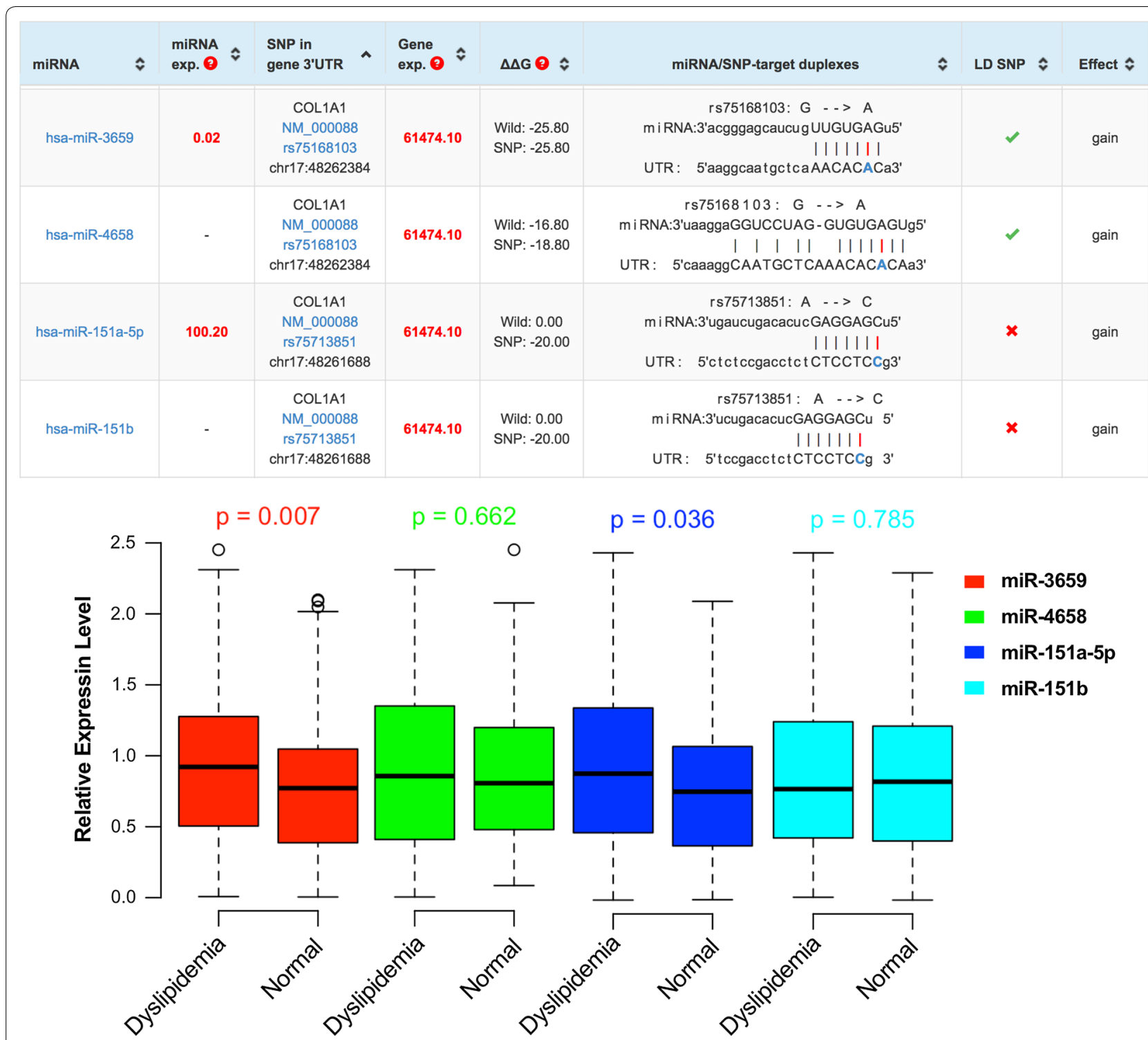

Fig. 6 Binding of miRNA to COLIA1 SNPS minor alleles and the relative expression level. On top of the figure shown bioinformatic analysis of potential miRNAs binding to COLIA1 SNPs polymorphisms and below was the relative expression level of the four miRNAs between two groups

processes just as obesity, dyslipidemia, diabetes, aging, and others $[43,44]$. Given their role in regulating transcriptional networks, miRNAs in adipose tissue might offer attractive biomarkers of adiposity as well as potential therapeutic targets for treating metabolic disorders [45].

Lots of evidences demonstrated that SNPs localized at miRNA binding sites (miRSNPs) could affect the binding of miRNAs to the target genes and in turn result in reduction or increase in translation of the target mRNA and altered susceptibility to disease [46]. In the current study, we used bioinformatic software to identified four
miRNAs which can bind SNPs in $3^{\prime}$ UTR in COL1A1, but only two miRNAs had statistical significance. After ROC curve analysis, we showed that miR-3659 in obese might be a potential biomarker for dyslipidemia diagnosis.

This study had several limitations. First, it did not report serum hormone levels which had potential impact on obesity and dyslipidemia. Second, it is a cross-sectional study that suggested hypotheses but failed to describe the relationship between the putative cause and effect. Third, it is a single-center study involving a small number of patients, and large-scale multicenter studies are necessary to verify our findings. Finally, the 

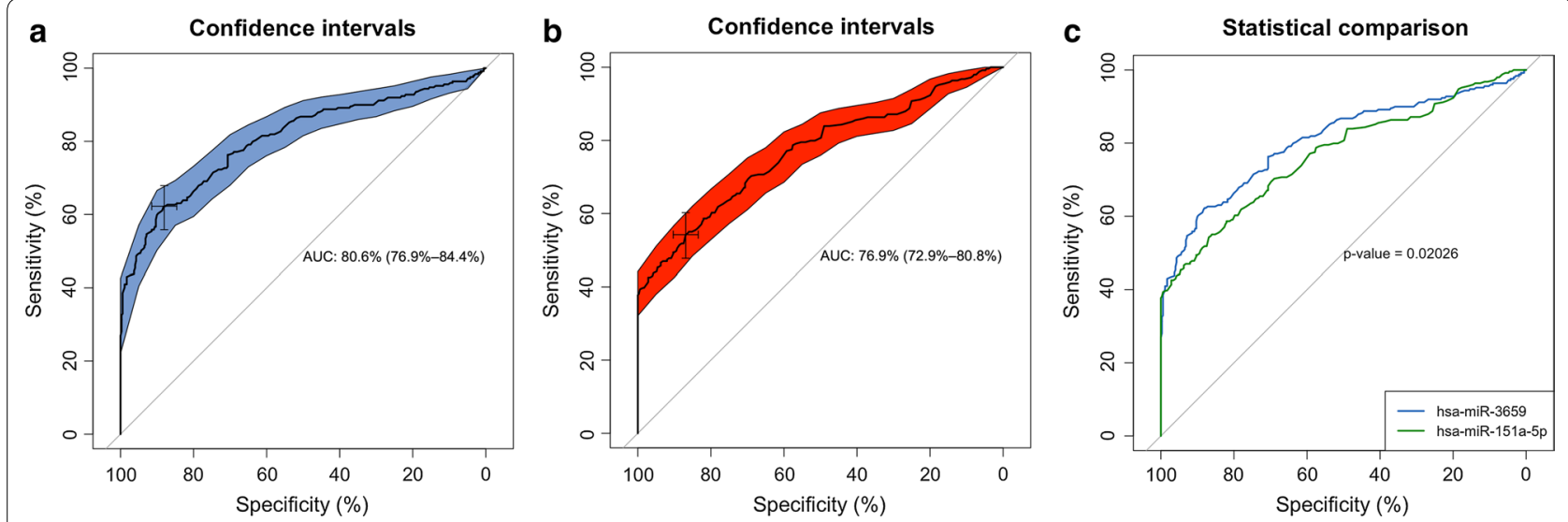

Fig. 7 ROC curves for the predictive value of miR-3659 and miR-151a-5p regarding dyslipidemia. The ROC curves for the predictive values of miR-3659 and miR-151a-5p to identify dyslipidemic patients from healthy controls

mechanisms of miR-3659 that regulated dyslipidemia in obese were not fully elucidated. The biological effects of microRNA in dyslipidemia need to be further determined via animal and cytology experiments in vitro.

\section{Conclusions}

After comprehensive WGCNA bioinformatics analysis and verification, we found that miR-3659 was significantly elevated in dyslipidemia patients with obesity and exhibited a good predictive effect on the incidence of dyslipidemia in obesity.

\section{Additional files}

\section{Additional file 1. Additional tables}

Additional file 2. Additional figures.

\section{Abbreviations}

GEO: Gene Expression Omnibus; WGCNA: weighted gene co-expression network analysis; GO: Gene Ontology annotation; KEGG: Kyoto Encyclopedia of Genes and Genomes pathway enrichment analyses; PPI: protein-protein interaction; MCODE: molecular complex detection; NCBI: National Center for Biotechnology Information; MM: module membership; Mes: module eigengenes; GS: gene significance; WC: waist circumference; SBP: systolic blood pressure; DBP: diastolic blood pressure; PP: pulse pressure; COL1A1: collagen type I alpha 1 chain; HDL-C: high-density lipoprotein cholesterol; LDL-C: low-density lipoprotein cholesterol; Apo: Apolipoprotein; TG: triglyceride; MetS: metabolic syndrome; BMI: body mass index; SNP: single nucleotide polymorphism; T2D: type 2 diabetes mellitus; TG: hypertriglyceridemia.

\section{Authors' contributions}

LM conceived the study, participated in the design, undertook genotyping, performed the statistical analyses, and drafted the manuscript. R-XY conceived the study, participated in the design, carried out the epidemiological survey, collected the samples, and helped to draft the manuscript. SY collaborated to the genotyping. S-LP, D-ZY and W-XL carried out the epidemiological survey and collected the samples. All authors read and approved the final manuscript.

\section{Author details}

${ }^{1}$ Department of Cardiology, Institute of Cardiovascular Diseases, The First Affiliated Hospital, Guangxi Medical University, Nanning 530021, Guangxi, People's Republic of China. ${ }^{2}$ Department of Pathophysiology, School of Premedical Science, Guangxi Medical University, Nanning 530021, Guangxi, People's Republic of China. ${ }^{3}$ Department of Molecular Genetics, Medical Scientific Research Center, Guangxi Medical University, Nanning 530021, Guangxi, People's Republic of China.

\section{Acknowledgements}

We thank all the staff in the laboratory.

\section{Competing interests}

The authors declare that they have no competing interests.

\section{Availability of data and materials}

The datasets used and/or analysed during the current study are available from the corresponding author on reasonable request.

\section{Consent for publication}

Not applicable.

\section{Ethics approval and consent to participate}

The research design was approved by the Ethics Committee. The First Affiliated Hospital of Guangxi Medical University (No: Lunshen-2011-KY-Guoji-001; March 7, 2011). All procedures are conducted in conformity to ethical standards.

\section{Funding}

The authors acknowledge the essential role of the funding of the National Natural Science Foundation of China (No: 81460169) and the Innovation Project of Guangxi Graduate Education in this motif.

\section{Publisher's Note}

Springer Nature remains neutral with regard to jurisdictional claims in published maps and institutional affiliations.

Received: 31 October 2018 Accepted: 5 January 2019

Published online: 14 January 2019

\section{References}

1. Boden G. Obesity, insulin resistance and free fatty acids. Curr Opin Endocrinol Diabetes Obes. 2011:18:139-43. 
2. Zalesin KC, Franklin BA, Miller WM, Peterson ED, McCullough PA. Impact of obesity on cardiovascular disease. Med Clin North Am. 2011;95:919-37.

3. Collaborators GBDO, Afshin A, Forouzanfar MH, Reitsma MB, Sur P, Estep K, Lee A, Marczak L, Mokdad AH, Moradi-Lakeh M, et al. Health effects of overweight and obesity in 195 countries over 25 years. N Engl I Med. 2017;377:13-27.

4. Abdulla J, Kober L, Abildstrom SZ, Christensen E, James WP, Torp-Pedersen C. Impact of obesity as a mortality predictor in high-risk patients with myocardial infarction or chronic heart failure: a pooled analysis of five registries. Eur Heart J. 2008;29:594-601.

5. Labounty TM, Gomez MJ, Achenbach S, Al-Mallah M, Berman DS, Budoff MJ, Cademartiri F, Callister TQ, Chang HJ, Cheng V, et al. Body mass index and the prevalence, severity, and risk of coronary artery disease: an international multicentre study of 13,874 patients. Eur Heart J Cardiovasc Imaging. 2013;14:456-63.

6. Esteller M. Non-coding RNAs in human disease. Nat Rev Genet. 2011;12:861-74

7. Guo H, Ingolia NT, Weissman JS, Bartel DP. Mammalian microRNAs predominantly act to decrease target mRNA levels. Nature. 2010;466:835-40.

8. Ryan $\mathrm{BM}$, Robles $\mathrm{Al}$, Harris CC. Genetic variation in microRNA networks: the implications for cancer research. Nat Rev Cancer. 2010;10:389-402.

9. Mishra PJ, Bertino JR. MicroRNA polymorphisms: the future of pharmacogenomics, molecular epidemiology and individualized medicine. Pharmacogenomics. 2009;10:399-416.

10. Wang WT, Chen YQ. Circulating miRNAs in cancer: from detection to therapy. J Hematol Oncol. 2014;7:86.

11. Martino F, Carlomosti F, Avitabile D, Persico L, Picozza M, Barilla F, Arca M, Montali A, Martino E, Zanoni C, et al. Circulating miR-33a and miR-33b are up-regulated in familial hypercholesterolaemia in paediatric age. Clin Sci (Lond). 2015;129:963-72.

12. lacomino G, Siani A. Role of microRNAs in obesity and obesity-related diseases. Genes Nutr. 2017;12:23.

13. Xanthakos SA, Jenkins TM, Kleiner DE, Boyce TW, Mourya R, Karns R, Brandt ML, Harmon CM, Helmrath MA, Michalsky MP, et al. High prevalence of nonalcoholic fatty liver disease in adolescents undergoing bariatric surgery. Gastroenterology. 2015;149(623-34):e628.

14. Barrett T, Troup DB, Wilhite SE, Ledoux P, Rudnev D, Evangelista C, Kim IF, Soboleva A, Tomashevsky M, Edgar R. NCBI GEO: mining tens of millions of expression profiles-database and tools update. Nucleic Acids Res. 2007;35:D760-5.

15. Gautier L, Cope L, Bolstad BM, Irizarry RA. Affy-analysis of Affymetrix GeneChip data at the probe level. Bioinformatics. 2004;20:307-15.

16. Gentleman RC, Carey VJ, Bates DM, Bolstad B, Dettling M, Dudoit S, Ellis B, Gautier L, Ge Y, Gentry J, et al. Bioconductor: open software development for computational biology and bioinformatics. Genome Biol. 2004;5:R80.

17. Horvath S, Dong J. Geometric interpretation of gene coexpression network analysis. PLoS Comput Biol. 2008;4:e1000117.

18. Langfelder P, Horvath S. WGCNA: an R package for weighted correlation network analysis. BMC Bioinform. 2008;9:559.

19. Miao L, Yin RX, Pan SL, Yang S, Yang DZ, Lin WX. Weighted gene coexpression network analysis identifies specific modules and hub genes related to hyperlipidemia. Cell Physiol Biochem. 2018;48:1151-63.

20. Yu G, Wang LG, Han Y, He QY. ClusterProfiler: an R package for comparing biological themes among gene clusters. OMICS. 2012;16:284-7.

21. Fuller TF, Ghazalpour A, Aten JE, Drake TA, Lusis AJ, Horvath S. Weighted gene coexpression network analysis strategies applied to mouse weight. Mamm Genome. 2007;18:463-72.

22. Smoot ME, Ono K, Ruscheinski J, Wang PL, Ideker T. Cytoscape 2.8: new features for data integration and network visualization. Bioinformatics. 2011;27:431-2

23. Bader GD, Hogue CW. An automated method for finding molecular complexes in large protein interaction networks. BMC Bioinform. 2003:4:2.

24. Miao L, Yin RX, Huang F, Chen WX, Cao XL, Wu JZ. The effect of MVKMMAB variants, their haplotypes and $G \times E$ interactions on serum lipid levels and the risk of coronary heart disease and ischemic stroke. Oncotarget. 2017:8:72801-17.

25. Miao L, Yin RX, Pan SL, Yang S, Yang DZ, Lin WX. Association between the MVK and MMAB polymorphisms and serum lipid levels. Oncotarget. 2017;8:70378-93.
26. Miao L, Yin RX, Wu JZ, Yang S, Lin WX, Pan SL. The SRGAP2 SNPS, their haplotypes and $G \times E$ interactions on serum lipid traits. Sci Rep. 2017;7:11626.

27. Miao L, Yin RX, Pan SL, Yang S, Yang DZ, Lin WX. BCL3-PVRL2-TOMM40 SNPs, gene-gene and gene-environment interactions on dyslipidemia. Sci Rep. 2018;8:6189.

28. Miao L, Yin RX, Yang S, Pan SL, Lin WX, Yang DZ. BRCA2 rs 9534275 polymorphism and serum lipid traits in the Maonan and Han populations. Int J Clin Exp Pathol. 2017;10:3163-78.

29. Zhou BF, Cooperative Meta-Analysis Group of the Working Group on Obesity in C. Predictive values of body mass index and waist circumference for risk factors of certain related diseases in Chinese adults_-study on optimal cut-off points of body mass index and waist circumference in Chinese adults. Biomed Environ Sci. 2002;15:83-96.

30. Miao L, Yin RX, Yang S, Huang F, Chen WX, Cao XL. Association between single nucleotide polymorphism rs9534275 and the risk of coronary artery disease and ischemic stroke. Lipids Health Dis. 2017;16:193.

31. Liu X, Wang L, Chi H, Wang J, Zheng Q, Li J, Li Y, Yang D. The SNP rs915014 in MTHFR regulated by MiRNA associates with atherosclerosis. Cell Physiol Biochem. 2018:45:1149-55.

32. Aroldi $A$, Lampertico $P$, Montagnino G, Passerini P, Villa M, Campise MR, Lunghi G, Tarantino A, Cesana BM, Messa P, Ponticelli C. Natural history of hepatitis $B$ and $C$ in renal allograft recipients. Transplantation. 2005;79:1132-6.

33. Chen X, Zheng Z, Chen L, Zheng H. MAPK, NFkappaB, and VEGF signaling pathways regulate breast cancer liver metastasis. Oncotarget. 2017:8:101452-60.

34. Greenland P, Knoll MD, Stamler J, Neaton JD, Dyer AR, Garside DB, Wilson PW. Major risk factors as antecedents of fatal and nonfatal coronary heart disease events. JAMA. 2003:290:891-7.

35. Yusuf S, Hawken S, Ounpuu S, Dans T, Avezum A, Lanas F, McQueen M, Budaj A, Pais P, Varigos J, et al. Effect of potentially modifiable risk factors associated with myocardial infarction in 52 countries (the INTERHEART study): case-control study. Lancet. 2004;364:937-52.

36. Guglielmo D, Hootman JM, Murphy LB, Boring MA, Theis KA, Belay B, Barbour KE, Cisternas MG, Helmick CG. Health care provider counseling for weight loss among adults with arthritis and overweight or obesity - United States, 2002-2014. MMWR Morb Mortal Wkly Rep. 2018:67:485-90.

37. Reddon H, Gueant JL, Meyre D. The importance of gene-environment interactions in human obesity. Clin Sci (Lond). 2016;130:1571-97.

38. Osman W, Tay GK, Alsafar H. Multiple genetic variations confer risks for obesity and type 2 diabetes mellitus in arab descendants from UAE. Int J Obes (Lond). 2018:42:1345-53.

39. Villegas-Martinez I, de Miguel-Elizaga I, Carrasco-Torres R, Marras C, Canteras-Jordana M, Yedra-Guzman MJ, Martinez-Villanueva M, TortosaConesa D, Martin-Fernandez J. The COL1A1 SP1 polymorphism is associated with lower bone mineral density in patients treated with valproic acid. Pharmacogenet Genomics. 2016;26:126-32.

40. Kathiresan S, Manning AK, Demissie S, D'Agostino RB, Surti A, Guiducci C, Gianniny L, Burtt NP, Melander O, Orho-Melander M, et al. A genomewide association study for blood lipid phenotypes in the Framingham Heart Study. BMC Med Genet. 2007;8(Suppl 1):S17.

41. Franssen R, Monajemi H, Stroes ES, Kastelein JJ. Obesity and dyslipidemia. Med Clin North Am. 2011;95:893-902.

42. Ebert MS, Sharp PA. Roles for microRNAs in conferring robustness to biological processes. Cell. 2012;149:515-24.

43. Seyhan AA. MicroRNAs with different functions and roles in disease development and as potential biomarkers of diabetes: progress and challenges. Mol BioSyst. 2015;11:1217-34.

44. Bonafe $M$, Olivieri F. Circulating microRNAs in aging. Oncotarget. 2015;6:1340-1.

45. Diniz GP, Huang ZP, Liu J, Chen J, Ding J, Fonseca RI, Barreto-Chaves ML, Donato J Jr, Hu X, Wang DZ. Loss of microRNA-22 prevents high-fat diet induced dyslipidemia and increases energy expenditure without affecting cardiac hypertrophy. Clin Sci (Lond). 2017;131:2885-900.

46. Ji X, Mao J, Zhou S. Rs739837 polymorphism in MiR-885-3p binding site within $3^{\prime}$-untranslated region of vitamin d receptor is associated with a decreased risk of pressure ulcers. Cell Physiol Biochem. 2017;44:2129-37. 